\title{
Enabling Tailored Music Programs in Elementary Schools: An Australian Exemplar
}

\author{
Katrina Skewes McFerran ${ }^{1}$, Alexander Hew Dale Crooke ${ }^{2}$ \\ ${ }^{1}$ The University of Melbourne, Australia \\ ${ }^{2}$ The University of Melbourne, Australia \\ Correspondence: Katrina Skewes McFerran, The University of Melbourne, Victoria, 3010 Australia
}

Received: September 9, 2014

Accepted: September 18, 2014 Online Published: September 30, 2014

doi:10.11114/jets.v2i4.536

URL: http://dx.doi.org/10.11114/jets.v2i4.536

\begin{abstract}
Participation in meaningful school music programs is the right of all children. Although music education is widely supported by policy, significant gaps exist in practice in most developed Western countries. These gaps mean the extrinsic and intrinsic benefits associated with participation in tailored programs are not equally available to all learners. School leaders have a critical role to play in determining the degree to which appropriate music programs are resourced in their schools and serve as both gate-keepers and enablers of these opportunities. The exemplary case study reported in this article describes a unique program that makes an interesting and complete contribution to knowledge. A string ensemble program in a socio-economically disadvantaged school provided "great opportunities to study music" that were "fun" and "calming" because of the "encouraging" approach adopted by teachers, except in relation to performances, which were "nerve-wracking". Learners, parents, teachers and leadership were all "proud" of the achievements of these young people, who often struggled in other academic areas and had escaped considerable trauma in their home countries. The results suggest that relevant music programs are not necessarily tied to a particular genre of music, but rather to the ways in which leaders and facilitators identify whether extrinsic or intrinsic benefits should be targeted and then tailor program designs to meet those needs.
\end{abstract}

Keywords: school music, policy, school leadership, extrinsic benefits, intrinsic benefits, teaching artist

\section{Introduction}

Equity in access to learning opportunities is one of the keystones to education policy in Western countries. The expectation that all children participate in comparable curricula has roots in the United Nations Convention on the Rights of the Child (Unicef, 1989), as well as more local education policy in each of the US (U.S. Department of Education, 2001), UK (Liberal Democrats, 2009) and Australian (Ministerial Council on Education, 2008) contexts. Despite this underlying drive towards equity, in practice a combination of socio-economic status, parent contribution to costs, and varying local policies means that some schools are better resourced than others.

Such factors mean school leadership must constantly make decisions about what programs to support and to cut. In this article, we argue that, despite the fact UNESCO (1999) has regularly committed to the principle that arts education be duly made a part of every child's life, the creative arts, and specifically music, are the programs most likely to be sacrificed unless leadership has a personal commitment to their value. Drawing on results from a study of Australian school principals to establish the rationale, we present an exemplary case study from one elementary school where a unique music program was able to flourish due to leadership support. We conclude with by highlighting issues for committed school leaders who are tasked with determining the most appropriate type of music programming to include in their school.

\subsection{Access to Music}

The achievement of equitable access to music in the United States provides a role model for other English-speaking countries in the developed world. According to official reports, music education is almost universally available in elementary schools (94\%); specialist teachers are responsible for $91 \%$ of that instruction; classes are held regularly (usually weekly); and state provided curriculum is used to ensure the provision of comparable programs (Parsad \& Spiegelman, 2012). In contrast, a recent report on trends in access to music in Australian schools revealed that only $23 \%$ 
of government funded schools provide a meaningful music education (Stevens, 2003). A between-states comparison showed that classroom music teachers were only available at an approximate average ratio of 1:500 students. Instrumental teachers were only available at a ratio of approximately 1:1500. The availability of music in privately funded schools in Australia is much higher (88\%), leaving families in the government system to "buy-in" music tuition through external services providers who are not on staff, but who provide group lessons for students, sometimes during class time. The situation in Canada is nearly as bleak (Coalition for Music Education in Canada, 2005), where only half of schools surveyed in a national study had adequate resources (funding, instruments and music rooms) in order to provide a meaningful music education, and only $50 \%$ of music programs were provided by specialists. Following a significant boost in the provision of funding specifically for music education (Ofsted, 2012), the UK fares a little better, with one report stating that $38 \%$ of schools inspected were providing a good or outstanding music education, $39 \%$ were reasonable, but $23 \%$ of programs were inadequate.

A reported downward trend in the provision of music programs in all countries, including the US, is cause for concern in this context. A recent report on access to music in Californian schools showed that while the student population is increasing, the provision of music education courses is dropping by a dramatic 50\% during the period of 1999-2004 (Music for All Foundation, 2004). The initially stellar reports on performance in the US means there is further to fall, and therefore the drop in other developed countries is less dramatic. However, the situation is urgent given that this decrease is occurring in a context where $93 \%$ of Americans agree that the arts are necessary for a well-rounded education (Bianchi, 2005). Kratus (2007) provides an insightful commentary on this decline, arguing for more relevant music programs in schools that reflect current cultural trends in music consumption. This trend is echoed in an international review of arts education programs commissioned by UNESCO (Bamford, 2006), which also highlights the gap between policy and practice in arts education, including contrasting statistics about participation of American children in a meaningful arts education. The various reviews suggest that the time is ripe for school leaders to reflect on what music they should be providing in schools, and why.

\subsection{The Importance of Music}

Across the literature, two main arguments are made for the value of music in schools and these can be classified as extrinsic and intrinsic benefits. Intrinsic benefits refer to the unique aesthetic and cultural outcomes accrued through participation in arts education. The importance of relevant musical curriculum does seem critical for intrinsic benefits, since music learning promotes ways of knowing the world and therefore musical genres and practices that reflect contemporary society are necessary for this to be possible (Bamford, 2006). Cultural identity is increasingly diverse, and so should music education be, both in terms of music traditions from different countries and the inclusion of technological strategies that reflect youth culture. When self-expression occurs in this context it can arguably be more authentic, which is often lauded as one of the primary benefits of musical participation (McCarthy, Ondaatje, Zakaras, \& Brooks, 2004). The other main benefit is in the development of skills increasingly valued in the knowledge economy (Jones, 2005), such as critical thinking (Catterall, 2009), imagination (Fiske, 1999), and a range of other learning characteristics valued in a rapidly shifting economic and cultural landscape (Lebler, 2007).

Extrinsic benefits involve the non-musical changes that result from participation in music. Many studies have investigated the correlations between music education and other academic outcomes, and a connection with IQ is regularly espoused (Schellenberg, 2006). The argument for extrinsic academic benefits is more often explained via the mechanism of engagement in learning activities (Ewing, 2010; Gill \& Rickard, 2011), and is particularly promoted for learners who are on the edge of participation (Rusinek, 2008); a cohort often noted to have less success engaging in traditional education experiences (Ofsted, 2012). Extrinsic links between music participation and wellbeing are also argued, with music therapy programs leading to improvements in social and emotional development (Kim et al., 2006) and connectedness (McFerran, Roberts, \& O'Grady, 2010), and tailored arts participation programs leading to improvements in social and emotional wellbeing (Vaughan, Harris, \& Caldwell, 2011). However, there is little evidence to support the premise that participation in traditional classroom based music education programs leads to these extrinsic benefits, suggesting that targeted music participation programs are more able to meet these additional needs.

\subsection{Enablers of Music Education}

Despite the many different arguments made for the benefits of meaningful music opportunities in schools, the gap between policy and practice is wide in both the US and other developed Western countries (Bamford, 2006). In order to understand better the barriers and enablers to meaningful music participation in schools in Australia, the first author invited school leaders to participate in a focus group discussion in April, 2011 (McFerran, 2011). Inductive qualitative analysis of the opinions shared by 4 principals, 3 assistant principals and 2 music coordinators revealed significant resourcing challenges that had to be met with creative solutions by committed leadership. Systemic barriers were described that resulted in negative cycles which undermined the potential for music to be used to achieve both intrinsic 
and extrinsic benefits. These leaders perceived a deficit in the music training of generalist teachers that led to a lack of confidence in the use of music to support the acquisition of academic skills such as literacy and numeracy. This deficit was particularly relevant in early years teaching where music has traditionally been used in the form of work songs and rhythmic chants to support fundamental learning. The potential for music to engage students in the school community was also highlighted. School leaders described a range of creative financial solutions that were required to counteract the diversion of funds into accounting for performance on numeracy and literacy. The false divide between resourcing for core academic subjects and for additional programs such as music created a constant challenge that they had to be manage carefully, often requiring financial contributions from parents so that music programs could survive. The school leaders in this study were committed to finding ways to resource music programs and some supported programs that were impressive in their breadth and/or depth. The value of disseminating examples of music programs that flourished despite systemic challenges became apparent and the first author sought out examples locally and internationally.

\subsection{Exemplars}

The most well known example of music programming despite contextual challenges is the El Sistema program originating in Venezuela (http://www.elsistemausa.org/el-sistema-in-venezuela.htm), and adopted in many parts of the US and around the globe. The program is described as a social transformation movement operated through collective music education that has been shown to empower young participants through their engagement in positive learning experiences (Majno, 2012). Group ensemble participation is critical to the El Sistema program, and this emphasis is also found in other exemplars of music programming that have succeeded despite a lack of resources.

A number of notable programs have focused on string ensembles. The Tower Hamlets String Teaching Project (Nelson, 1985) was established in the UK in the late 1970s, similarly to El Sistema, and was inspired by an American program run through the University of Illinois by Paul Rolland (Rolland, 1974). This program had more traditional music instruction goals but also focused on group learning in a positive environment that was adjusted to the abilities of a previously untrained group of learners. A similar program called ColourStrings in Finland has been reported in the literature (Murphy, Rickard, Gill, \& Grimmett, 2011), and the same authors discussed the difficulties faced in establishing a group string program in regional Australia. The importance of taking adequate time to tailor the program to the needs and interests of the school community is particularly noted in this paper.

The potential for intrinsic and extrinsic benefits through targeted music programs utilising group ensemble experiences is supported through the literature and the need for examples of exemplary programs for school leaders is apparent. This article describes a case study investigation of one such program in Australia, called the Harmony in Strings project. The purpose of the research was to identify the key features which were perceived to be critical by various stakeholders in the program, so that recommendations could be generated that reflected the local context within the international scene. A case study design was chosen in order to examine the unique facets of the phenomenon in its real-life context in detail. Yin (2013) described exemplary case studies as those that are interesting, complete and contribute to knowledge, which captures the characteristics of this research. Inductive qualitative analysis of interviews was used in order to address Yin's requirement that the case be engaging to the reader, and sufficient evidence of the analytic process is provided in order to ensure that the claims are contextually located.

\section{Method}

\subsection{The Harmony in Strings Program}

The instrumental string program investigated in this case study took place over a three-year period in an inner suburban elementary school. The majority of the school population lived locally and was from non-English speaking refugee or migrant backgrounds, primarily originating from Sudan and Vietnam. Many families were experiencing significant socio-economic disadvantage and were challenged by multiple issues related to trauma and settlement; lack of pre schooling and early schooling; language comprehension; as well as behavioural, emotional and learning difficulties. The primary aim of the program was to improve student social and emotional wellbeing, with the longer-term goal of improving educational outcomes as a result of student's engagement with an instrument.

The program comprised weekly tuition over the course of the school year in violin or cello, and was compulsory for all students in Years Four to Six (ages approximately 9-12 years old). Student numbers were relatively stable across the duration of the program, with 60 students participating in 2011, 57 students in 2012, and 64 students in 2013. Learners did not take instruments home to practice, but instead participated in two small group lessons of 30 minutes each week, as well as After School Music Club which was available twice per week. There was no financial cost for participation.

Two teaching artists ran the program since its inception, and were employed by The Song Room, a national not-for-profit organization that supports music and arts programs in schools classified as having a low socio-economic status. The program was funded through a series of bequests made by another local philanthropic organization. The 
pedagogical model retrospectively identified by the teaching artists emphasized a supportive, positive, respectful environment; inclusivity; flexibility; student leadership; motivation through ownership of learning; and independence (reference to be added after review). The teaching methods used by the artists involved a focus on: connection to instrument; aural transmission; games; repertoire; musical exploration; as well as improvisation and composition. The researchers were invited to investigate the program by the program providers, but were not contracted to do so and undertook the analysis independently.

\subsection{Data Collection}

University and relevant education office committees provided ethical clearance for the research. Data were collected in the form of individual interviews with seven music students whose parents provided consent, two parents, the two teaching artists and the school principal. An interview was conducted with the teaching artists first, where they were asked to describe the program. Very few prompts were required to guide the open-ended interview, which lasted 95 minutes. Students and parents then participated in interviews that were also open-ended, but required more prompts to encourage participants to provide further descriptions. The first question was: "Can you please tell me about the Harmony in Strings program and how it has been for you/your child." Further prompts included: what is your favourite memory, what is your worst memory, would you recommend the program to other students, why/why not, what did you notice about other people that were in the program? Interviews with students and parents lasted between 10 and 20 minutes and were conducted in the music room during class time. The school principal was interviewed last and once again required minimal prompting to solicit their perspective on the program, both historically, currently and the perceived benefits and limitations. This interview closed after 30 minutes due to time constraints and both interviewee and interviewer were aware of the length of time available and focused discussion to solicit a succinct but comprehensive view. Interviews were transcribed in real time.

\subsection{Data Analysis}

Inductive qualitative analysis was used to work with the data collected through the interviews in an ongoing way. A number of principles informed by grounded theory were applied including: theoretical sampling (where contributors are specifically selected for their ability to inform the emerging interpretations), constant grounding in the data (where participant words are used for in-vivo coding and initial category labeling), abductive logic (where interpretations are made through a process of contemplating the implications of inductively derived categories and tested using deductive categorization), and saturation (where data collection ceases when new ideas are no longer being presented) (Dey, 2007). Although these principles were applied, a grounded theory analysis was not considered suitable for the investigation of this exemplary case (by definition unique rather than sufficient for making generalistions or abstracting to the level of theory) and instead a generic qualitative inductive analysis was used in order to remain at a descriptive, rather than theorizing level (Hood, 2007).

Student interviews were analysed in the first wave, and six key themes were identified. These were then considered in the context of the two parent interviews and interesting connections and diverse emphases were noted. Analysis of the teaching artists descriptions were then compared to the students' themes and the principal's interview was used to provide context for understanding the nuance of the themes, which is not always captured in the words themselves. The inductively identified themes are presented below, with quotes to illustrate the degree to which these are grounded in the data and additional commentary added from parents, teaching artists and the principal to illustrate the interaction between the perceptions of the informants and the cultural, historical, systemic and musical conditions that shaped the program.

\section{Results}

Six main themes were inductively derived from the interviews with students. Some of these appeared to be closely related to ideas that have been presented in the literature on musical participation previously, such as It was fun (McFerran \& Teggelove, 2011; McFerran \& Crooke, In press), and The teachers were encouraging (Hattie \& Yates, 2013). Others seemed more specific to the particular context of this program: "It's a good opportunity to study music, I feel proud of myself, as well as it helps me be calm and I had to deal with nerves at performances". The categories that represented the more unique facets of the program will be presented first, contextualized with insights garnered from interviews with other informants.

The theme"It's a good opportunity to study music" draws its label from the words of one of the more articulate, older girls who participated in the interviews. Although other students did not use such refined language in their descriptions, the general tone of their reflections often conveyed a similar message about their experience of the program that extended beyond being lucky or having fun. This recognition that participation in a strings program gave them opportunities that were not usually available to new migrants and refugees was also present in the description of one of the parents, of Vietnamese origin, who said "I like her to play going forward. She has the cello and a future for her to 
learn more. She likes that. She learns more, and she has a teacher so that's good. A job is important, for the future, you know." In reflecting on the interviews, this way of conceiving of the program as a "good opportunity" that emerged was described by all seven students when asked to reflect on the program, as can be seen in Table 1 .

Table 1. Theme: It's a good opportunity to study music

\begin{tabular}{ll}
\hline Source & \multicolumn{1}{c}{ Quote } \\
\hline Student 1 & I don't usually play music or instruments or any stuff like that \\
Student 2 & I thought it would be good for me \\
& You can experience new sounds \\
I was excited because I could start playing & It's a good opportunity really. \\
Student 3 & I feel good because it's a good talent to learn \\
I just want to learn how to play an instrument and go with the flow. & Learn more about music \\
Student 5 & We were able to play the piano (begins playing the piano in the background) \\
Student 6 & Getting to be in an orchestra \\
Student 7 & I really like music and I've always wanted to try every instrument \\
& If you're good, you'll get a better life
\end{tabular}

Closely related to the suggestion that the strings program was a good opportunity, was the way that the students described how I feel proud of myself. Although references to self-esteem proliferate the literature, the sense of pride captured in the reports of these students was more immediate and external. The students would often hold their backs a little straighter when they offered these statements, and it was clear that they felt recognized by others, whether this was peers, family, community or school professionals. Once again, the migrant and refugee status of the families seemed important to the creation of this category, since it was clear that having the "opportunity" was the first step and was associated with a gratitude to others. The kind of pride captured in this category was related to making something of the opportunity they had been offered, which influenced their sense of how they were seen. For the mother of a boy who had a severe communication problem, being able to see their son participate successfully in the cello program made them proud, both of their son and their ability to see that their son was learning something: "I don't know what he's learning or why he's learning. But I know he likes it. All the time he goes on to the computer and listens (to cello) in there, and he enjoy it. I know he likes it." The teaching artists reported this young man's achievement with a sense of pride also, knowing that their first attempts at speaking English had been uttered in the context of a cello lesson, and that music may have offered them a way of connecting to the world that had been lost in the transition between countries. The student pride was matched by the emotional overtones of the adult informants, who valued the opportunity to observe them succeeding, as represented in Table 2.

Table 2. Theme: I feel proud of myself

\begin{tabular}{|c|c|}
\hline Source & Quote \\
\hline \multirow[t]{2}{*}{ Student 1} & I liked to hold a big instrument \\
\hline & I was proud of myself coz I had done something that was good. \\
\hline \multirow[t]{2}{*}{ Student 3} & Only a few of us was chosen. \\
\hline & My parents are proud of me playing an instrument. \\
\hline Student 4 & People have tears of joy and that's when people congratulate other people \\
\hline Student 7 & I'm representing my school. \\
\hline \multicolumn{2}{|c|}{$\begin{array}{l}\text { The immigrant and refugee status of the families involved in the program also bought some challenges in relation to } \\
\text { participation in the group strings program. Although the category It helps me be calm seems innocuous in some ways, it } \\
\text { was an important statement for the two Sudanese boys and one older Vietnamese girl who were involved in the program. } \\
\text { The school principal explained that prior to } 2009 \text {, the families attending the school had been primarily Chinese and } \\
\text { Vietnamese, and that within the space of a single year the Sudanese families grew to comprise } 36 \% \text { of the school } \\
\text { community. This change in demographic makeup was significant, not just for the Sudanese families fleeing mass } \\
\text { genocide in their country, but also for teaching staff who had previously dealt with cultural groups who were essentially }\end{array}$} \\
\hline
\end{tabular}


compliant compared to the more recent families who had become increasingly physical and expressive. The following story from the school principal explains why using music to experience a sense of "calm" was so important and Table 3 presents the comments made by the three students.

We've always had social-emotional work to do here, but it's been very values based. And that didn't really work, because they could say it and not do it. So we looked at emotional literacy - all feelings are OK. Then teaching those strategies to students - when I'm feeling like this, this is what I need to do; I need to make a plan and not just react to feelings. Then we put things in place to teach emotional literacy. We couldn't talk with parents about feelings because they were also traumatised. So we shared all the strategies for calming down across all the different professionals that worked with the students - in music club, library club, all the people in the community. Now this year, we feel it's the right time to invite the parents into the discussion. And it's working.

Table 3. Theme: It helps me be calm

\begin{tabular}{ll}
\hline Source & \multicolumn{1}{c}{ Quote } \\
\hline Student 1 & I'm just calm and relaxed and happy \\
Student 4 & It just calms you down \\
Student 5 & If you're sad it will calm you down \\
& Calm and relaxed when I play it \\
\hline
\end{tabular}

The high levels of anxiety associated with trauma might also explain the nervousness described by four of the students when probed about any challenges they had with the program. Although performance anxiety is a common phenomenon, it was clear from the descriptions that some students preferred the safety of in-school music time rather than the public performances that were regularly associated with the program. Both the teaching artists and the principal believed that performances were very positive for the program and in many ways were a valuable way of "reporting" on the success of the program, both to families and benefactors. Students were not required to participate in performances, and there were times when students chose not to attend. This kind of flexibility likely went some way toward reducing possible detrimental effects of performance participation.

Table 4. Theme: I had to deal with nerves at performances

\begin{tabular}{|c|c|}
\hline Source & Quote \\
\hline Student 1 & Nervous and a little shy \\
\hline Student 3 & I used to be nervous to go up on stage and now I'm not anymore \\
\hline Student 5 & Had butterflies, and I tried just to look at my violin \\
\hline Student 7 & I kind of get stage fright a bit. \\
\hline \multicolumn{2}{|c|}{$\begin{array}{l}\text { The student descriptions matched the views of the teaching artists who explained that they did not pressure students to } \\
\text { participate, but rather adopted a positive, flexible and responsive approach that encouraged students to explore. The } \\
\text { teaching artists described how many of the students had never encountered music before and how they had developed } \\
\text { an understanding that they "needed to be positive all the time." The approach of the teaching artists evolved over the } \\
\text { three-year period to a partnership model that was student-led rather than curriculum driven. As noted in the description } \\
\text { of their pedagogical approach, they found that aural learning (without sheets of music) was more success oriented than } \\
\text { focusing on pieces of paper. This evolved approach was also influenced by their own performance backgrounds, as folk } \\
\text { and improvising musicians who, whilst trained in the classical tradition of Western art music, had both moved away } \\
\text { from the strict rules of their own learning experiences and towards the kinds of approaches that they now adopted in } \\
\text { teaching. The students' experience of their relationships with the teaching artists was positive, and they consistently } \\
\text { described how The teachers were encouraging (Table 5). }\end{array}$} \\
\hline \multicolumn{2}{|c|}{ Table 5. Theme: The teachers were encouraging } \\
\hline Source & Quote \\
\hline Student 1 & Nice and kind and good to me. \\
\hline Student 2 & They don't make it really hard. \\
\hline Student 3 & They're always happy, smiling \\
\hline Student 5 & In the way she tells me to keep trying \\
\hline Student 6 & They're very helpful. \\
\hline Student 7 & She concentrates on everyone \\
\hline
\end{tabular}


The students also described their own experiences in a very positive way, and although there are not quotes included from every student in the category It was fun (Table 6), the informants were universally positive. Apart from the comments about performance anxiety, the only negative comments solicited through very specific attempts to encourage a balanced view were from one girl (the very articulate Student 5), expressing that they might have liked to also try another, non-string instrument; and one young man noting that sometimes they had to stop doing something that was fun to come to music lessons.

Table 6. Theme: It was fun

\begin{tabular}{ll}
\hline Source & \multicolumn{1}{c}{ Quote } \\
\hline Student 2 & It's very fun and easy to play. \\
Student 3 & I love it, it's really fun to learn an instrument \\
& It feels happy and joy inside \\
Student 4 & When you're playing it, you just let it go. \\
Student 6 & I liked last year because we played games like music games \\
& Got to watch entertainment when I was bored, \\
\hline
\end{tabular}

\section{Discussion}

One of the unique facets of this particular music program was the leadership in the school. The principal was the gate-keeper and the primary enabler of the music program. Their own musical background had involved opera singing and they reflected openly on how their personal experiences with music had led them to believe that music could be used to meet the needs of their diverse school community.

Learning and performance of music was what bought everyone together (in that opera group). It taught me that music transcends all differences. Here was this really diverse group of people that all sang and were all from different walks of society and could get together and work together and put on these fantastic performances.

The teaching artists also described how involved the principal was in the music program. "She will come in and say 'You just learn it like reading and maths.' She puts it on the same level and tells the kids that, and it means the interaction is always happening with the whole school community." This high level commitment to the music program was critical, first in seeing the potential for it to be helpful, and then in finding the funding to make it happen. Whilst the principal's particular musical history is unique, the focus group study of another seven Australian school leaders (McFerran, 2011) suggests that this is necessary in order for music programs to flourish. Not all the leaders in the previous study had musical careers themselves, and some spoke openly about their personal lack of musical ability, but each was a lover of music and believed in its value.

The kind of value placed on music programs does vary however. In this case study, the primary objective of the program was extrinsic - to improve social and emotional wellbeing, and as a result, to improve academic engagement. The program was therefore tailored to this end, with encouragement and creation of a positive environment routinely being privileged over musical outcomes. Although measures were not taken before and after participation, the informants described extrinsic benefits being achieved through using the music to stay calm, have fun and as a result, experiencing a strong sense of pride. It is interesting to note, however, that both parents and students fundamentally perceived the intrinsic benefits as being core to their experience. The theme capturing the perception that music was "a good opportunity" emphasized the cultural value of instrumental skills, and to some degree, the opportunity to participate in the "high" culture that the strings represent. The students and parents seemed to value the intrinsic over the secondary, extrinsic benefits.

The literature suggests that the different types of benefits are best achieved by tailoring programs to meet the specific intrinsic or extrinsic aims of the program (Crooke \& McFerran, 2014). Wellbeing benefits do not inevitably flow from participation in classroom music, since success and failure to meet curricular goals can result in positive and negative perceptions. Some commentators have argued that this lack of transfer of benefits is because music programs do not employ music genres that are relevant to people's lives outside of the school environment (Bamford, 2006; Kratus, 2007). Whilst this relevance-based argument is logical, the exemplary case explored here suggests otherwise. Although the teaching artists described how they had to adjust their teaching styles to engage the students in ways that were very different from their teaching in the wealthier private school system, they did not have to change their instrument. The violin and cello have little inherent relevance to the families in the school, but the way the program was taught made it accessible and meaningful. The teaching artists described helping students learn songs they had been listening to on the Internet, as well as introducing music from a range of different cultures. The repertoire was not dominated by the canons of Western art music, but nor was this repertoire excluded. The teaching artists regarded flexibility and 
responsivity as critical dimensions, which in keeping with the notion that tailored music programs are able to meet the additional needs of students, whereas curriculum based teaching is better suited to the achievement of academic outcomes, both in music and other cognitive domains.

The assumption that performance should be a part of the music program deserves further reflection. The students in this study did not always derive further benefit from the opportunities to perform, and in some cases, the experience was negative. This issue has come to light in the music therapy literature, where the first author has provided a critique of this practice, based both on an interview study with music therapy facilitators (O'Grady \& McFerran, 2012) and clinical experiences working with adolescents (McFerran, 2010). A careful inspection of the interview transcripts does not reveal any leading by the interviewer towards this particular finding and it seems to have emerged naturally as one of the few negative aspects of the experience for some of the learners. Performances are neither inherently bad, nor inherently positive, but they should be carefully considered and not assumed to be the best way of concluding or sharing achievements, particularly at a time when recording is feasible with little technical expertise.

The limitations inherent in case study designs are also the strengths of this investigation. No attempts have been made to generalize from the unique experiences of participants in this program, however the nuanced descriptions that have been provided may inspire other music program facilitators to consider how a range of instruments, genres and leadership styles might be employed in a similar context. In addition, although the support of the school principal seems fundamentally rooted in their own personal experiences with group music making, this commitment to the value of music has been noted in a previous study and may well be a critical feature in other successful programs. The importance of leadership support is widely reported anecdotally, and this case provides some possible explanation for why this is so.

\section{Conclusion}

The importance of opportunities to access relevant music experiences in schools is broadly supported by policy, but significant gaps exist in practice. This exemplary case study illustrates the extent to which commitment from school leadership can address this gap and meet the unique needs of the students in their local context. Whether students are young people with significant social and emotional challenges, or those for whom music skills may provide a platform for the kinds of innovative and creative thinking valued by the new knowledge economy, needs to be taken into consideration. The assumption that one model of music programming will best suit all students is not supported by the literature, nor by this case study. What is more clear is that school leaders carry responsibility not only for resourcing programs, but for identifying what type of music program to prioritise based on their understanding of the school community. Music facilitators, whether they are teachers or artists, are then charged with developing programs that are relevant, not because of the genre or the instrument, but because of the way in which opportunities are offered. With this knowledge in hand, both extrinsic and intrinsic benefits can be achieved through musical participation.

\section{Acknowledgements}

The Song Room facilitated this research by establishing the relationship between the school and the primary researcher. The Buckland Foundation provided funding for the program over the three years.

\section{References}

Bamford, A. (2006). The wow factor: Global research compendium on the impact of the arts in education. Berlin: Waxmann Verlag.

Bianchi, J. (2005). New Harris poll reveals that 93 percent of Americans believe that the arts are vital to providing a well-rounded education. Retrieved from http://www.americansforthearts.org

Catterall, J. (2009). Doing well and doing good by doing art: The long term effects of sustained involvement in the visual and performing arts during high school. Los Angeles, CA: Los Angeles Imagination Group.

Coalition for Music Education in Canada. (2005). Music Education "State of the Nation" Benchmark Study. Retrieved from http://musicmakesus.ca/wp-content/uploads/2010/10/EnglishMusicReport.pdf

Crooke, A., H. D., \& McFerran, K.S. (2014). Recommendations for the investigation and delivery of music programs aimed at achieving psychosocial wellbeing benefits in mainstream schools. Manuscript submitted for publication.

Dey, I. (2007). Grounding Categories. In A. Bryant \& K. Charmaz (Eds.), The SAGE handbook of grounded theory, 167-190. Thousand Oaks, CA: SAGE.

Ewing, R. (2010). The Arts and Australian Education: Realising potential. In C. Glascodine (Ed.), Australian Education Review, 58,76. Camberwell, Victoria: Australian Council for Educational Research.

Fiske, E. B. (Ed.). (1999). Champions of change: The impact of the arts on learning. Washington, DC: Council of Chief 
State School Officers.

Gill, A., \& Rickard, N. (2011). Non-musical Benefits of School Music Instruction. In S. N, Rickard. \& K. S. McFerran (Eds.), Lifelong Engagement with Music, 59-74: Nova Science Publishers, Inc.

Hattie, J., \& Yates, G. C. R. (2013). Visible learning and the science of how we learn. New York, NY: Routledge.

Hood, J. C. (2007). Orthodoxy vs. power: The defining traits of grounded theory In A. Bryant \& K. Charmaz (Eds.), The SAGE handbook of grounded theory (pp. 151-164). Thousand Oaks, CA: SAGE.

Jones, P. M. (2005). Music Education and the Knowledge Economy: Developing Creativity, Strengthening Communities. Arts Education Policy Review, 106(4), 5-12. http://dx.doi.org/10.3200/AEPR.106.4.5-12

Kim, S., Kverno, K., Lee, E. M., Park, J. H., Lee, H. H., \& Kim, H. L. (2006). Development of a music group psychotherapy intervention for the primary prevention of adjustment difficulties in Korean adolescent girls. Journal of child and adolescent psychiatric nursing, 19(3), 103-111. http://dx.doi.org/10.1111/j.1744-6171.2006.00058.x

Kratus, J. (2007). Music Education at the Tipping Point. Music Educators Journal, 94(2), 42-48. http://dx.doi.org/10.1177/002743210709400209

Lebler, D. (2007). Student-as-master? Reflections on a learning innovation in popular music pedagogy. International Journal of Music Education, 25(3), 205-221. http://dx.doi.org/10.1177/0255761407083575

Liberal Democrats. (2009). Equity and excellence. Policies for 5-19 education in England's schools and colleges. Policy paper 89. London: Liberal Democrats.

Majno, M. (2012). From the model of El Sistema in Venezuela to current applications: learning and integration through collective music education. Annals of the New York Academy of Sciences, 1252(1), 56-64. http://dx.doi.org/10.1111/j.1749-6632.2012.06498.x

McCarthy, K., Ondaatje, E., Zakaras, L., \& Brooks, A. (2004). Gifts of the muse: Reframing the debate about the benefits of the Arts. Santa Monica, CA: RAND.

McFerran, K. (2010). Adolescents, music and music therapy: Methods and techniques for clinicians, educators and students. London: Jessica Kingsley Publishers.

McFerran, K. S. (2011). You're the voice: Principals views about music in schools. Australia: The University of Melbourne Retrieved from http://conservatorium.unimelb.edu.au/staff/katrinaskewesmcferran.

McFerran, K. S., \& Teggelove, K. (2011). Music Therapy with Young People in Schools: After the Black Saturday Fires. Voices: A World Forum for Music Therapy, 11(1).

McFerran, K.S., \& Crooke, A. H. D. (In press). Music Therapy and Mourning. In J. W. Davidson \& S. Garrido (Eds.), Music and Mourning: Interdisciplinary Investigations. Surrey, England: Ashgate Publishing Ltd.

McFerran, K.S., Roberts, M., \& O'Grady, L. (2010). Music therapy with bereaved teenagers: A mixed methods perspective. Death Studies, 34(6), 541-565. http://dx.doi.org/10.1080/07481181003765428

Ministerial Council on Education, Employment, Training and Youth Affairs. (2008). Melbourne Declaration on Educational Goals for Young Australians. Melbourne: Ministerial Council on Education, Employment, Training and Youth Affairs Retrieved from http://www.nap.edu.au/_Documents/PDF/National Declaration on the Educational Goals for .pdf.

Murphy, F., Rickard, N., Gill, A., \& Grimmett, H. (2011). Informing new string programmes: Lessons learned from an Australian experience. British Journal of Music Education, 28(3), 285-300. http://dx.doi.org/10.1017/S0265051711000210

Music for All Foundation. (2004). The Sound of Silence - The Unprecedented Decline of Music Education in California Public Schools. Retrieved from http://music-for-all.org/sos.html

Nelson, S. M. (1985). The Tower Hamlets Project. British Journal of Music Education, 2(1), 69-93. http://dx.doi.org/10.1017/S0265051700004617

Ofsted. (2012). Music in schools: Wider still, and wider: Quality and inequality in music education 2008-11. Manchester: Office for Standards in Education.

O’Grady, L. \& McFerran, K.S. (2012). Performances in Music Therapy: Considerations from Community Music Therapy Discourse for Australian Practice, British Journal of Music Therapy, 26(1), 24-38.

Parsad, B., \& Spiegelman, M. (2012). Arts Education in Public Elementary and Secondary Schools: 1999-2000 and 
2009-10 (NCES 2012-014). Washington, DC: National Center for Education Statistics, Institute of Education Sciences, U.S. Department of Education.

Rolland, P. (1974). The Teaching of Action in String Playing. Urbana, IL: Illinois String Research Associates.

Rusinek, G. (2008). Disaffected learners and school musical culture: an opportunity for inclusion. Research Studies in Music Education, 30(1), 9-23. http://dx.doi.org/10.1177/1321103X08089887

Schellenberg, E. G. (2006). Long-term positive associations between music lessons and IQ. Journal of Educational Psychology, 98(2), 457-468. http://dx.doi.org/10.1037/0022-0663.98.2.457

Stevens, R. (2003). National report on trends in school music education provision in Australia (pp. 190). Melbourne: Music Council of Australia.

U.S. Department of Education. (2001). No Child Left Behind. Washington, DC: U.S. Department of Education, Office of the Secretary.

Unicef. (1989). Convention on the Rights of the Child. Geneva.

United Nations Educational, Scientific and Cultural Organization. (1999, November 3). International appeal for promotion of the Arts in education. Paper presented at the General UNESCO conference, Paris.

Vaughan, T., Harris, J., \& Caldwell, B. J. (2011). Bridging the gap in school achievement through the Arts: Summary report, 36. Melbourne: Song Room.

Yin, R. K. (2013). Case study research: Design and methods: SAGE

\section{(cc) $\mathrm{EY}$}

This work is licensed under a Creative Commons Attribution 3.0 License. 